\title{
Old Book, New Look: Exploring Resilience and Self-Help in The Power of Sympathy and Educated
}

\section{Hamideh Mahdiani}

Institute for History, Theory, and Ethics of Medicine, University of Mainz, Germany

\begin{abstract}
This paper aims to portray how certain literary works, when read closely, initiate ideas of resistance, resilience and self-awareness, which are at the same time part of the equipment of self-help. This concept of self-help, I propose, is communicated through different forms of self-education. My readings of what is considered by many to be the first American novel, The Power of Sympathy(1789), and the very recent memoir by Tara Westover, Educated(2018), are exemplary studies for such claims. I maintain that where $18^{\text {th }}$ century conduct books intended to educate the younger minds of “the fairer sex," today's memoir does something quite similar under a different guise: that of human resilience. In order to show the relation between resilience and self-help, I will proceed in three steps: first, I will briefly review the two concepts of self-help and resilience; second, I will provide close readings of the chosen texts from the perspective of resilience research: and third, thereby I will conclude by proposing that resilience is understood as a means to maintain ability and fend off dis-abilities-but as such it also unwittingly holds up normality and normativity without questioning the problematic nature of a society that demands such defenses.
\end{abstract}

Keywords-Human Resilience, self-help, self-awareness, education, Power of Sympathy, Educated.

\section{SELF-HELP AND RESILIENCE}

This paper is not an example of a reading of selfhelp books per se, it rather aims to portray how certain literary texts, when read closely, initiate ideas of resistance, resilience, and self-awareness, which are at the same time part of the equipment ofself-help. What is self-help? The APA Dictionary of Psychology describes self-help as selfguided improvement (2007). Despite its present popularity and household name status, self-help tradition has its roots centuries ago, whenit was common to utilize topics such as economic, intellectual, or emotional to educate the reader in social norms under the umbrella ofconduct books. The Greek poet Hesiod's Works and Days (700 BC), a didactic poem addressed to Hesiod's brother in the arts of agriculture, is an antecedent. Samuel Smiles' Self-Help (1859), perhaps the first self-help book in the modern sense published in Great Britain, opens with this line: "Heaven helps those who help themselves" (p.15). In the North American context, Ralph Waldo Emerson's essay entitled Compensation (1841) writes "every man in his lifetime needs to thank his faults... and acquire habits of self-help... our strength grows out of our weakness (p.22). All such works communicate some form of ISSN: 2456-7620

https://dx.doi.org/10.22161/ijels.54.48 a guidance to the reader.As is defined by Sarah E. Newton, conduct books refer to "a text that is intended for an inexperienced young adult or other youthful reader[...] whose primary aim is [...] to encourage ideal conduct in white, generally middle-class children, young men, or young women" (1996, p.4).

As early as the nineteenth century, men were not the only authors of such books. Women also authored conduct books, many of which focused on the role of knowledge and education. In her Letters to Young Ladies (1833) and Letters to My Pupils (1850), for example, Sigourney discusses conversation, reading aloud as parlor entertainment, and letter-writing in the contexts of a republican ideal of womanhood, whereby she represents women as selfeducated, encourages girls to improve themselves via reading, and further persuades women to study" epistolary composition" (Letters,p.116). The same line of argument, perhaps delivered more persuasively, is taken up by Farrar in her The Young Lady's Friend (1836). For Farrar, an ideal woman is among other functions an agreeable and knowledgeable partner in conversation (Young Ladies, p.3940). 
Although by the advent of novels, conduct books had lost their popularity, the final third of the 20th century witnessed a boom in a genre which follows the same approaches: self-help books. In an astonishing work of criticism, titled Women and Self-Help Culture: Reading between the Lines (1992), Simonds, who reviews self-help books from 1963 into the 1980s, argues that the genre's continued success is indicative of readers' search for meaning. Observing "the tremendous growth in self-help publishing... [and] in self-improvement culture" (McGee, p.12),some social theorists have argued that "the late-20th century preoccupation with the self serves as a tool of social control: soothing political unrest...[for] one's own pursuit of self-invention" (McGee, p.22-23). Simonds' research concludes that the self-help genre tends to recommend individual change rather than social change. In a similar vein, Graaff and Klepper understand self-help discourses as figuring both on an individual and a media level, where the former points to the "action or faculty of using one's own efforts and resources to achieve something" (p.74) and the latter, to "mass-circulated advice and guidance on how to 'adopt new forms of conduct' in order to improve specific 'arenas of [one's life]' (p.74).I would like to argue that the genre has yet another guise; one can find the theme of selfhelp in other literary forms such as novels and memoirs. To expand on this claim I need to discuss yet another timely topic: human resilience.

What is resilience? It is much harder to define this term than it is to define self-help. Over the last five decades, resilience researchers have worked on the dynamic connection between stress and resilience; what differentiates a resilient from a non-resilient individual; the neurochemical, genetic, and epigenetic mechanisms thought to be the neurobiological foundation of resilience or vulnerability to a stress-related situations; and whether the ability to cope with high levels of stress is innate, inborn, inherited, and/or acquired through specific training (e.g., through a stress inoculation process) or the result of some combination of all of the above ${ }^{1}$. There has been considerable divergence in the literature with regard to the definitions, criteria, or standards for resilience; whether it is a trait, a process, or an outcome variable; whether it is enduring or situation-specific; and whether survival in the face of adversity is required for resiliency to be demonstrated. Psychiatrists like Luthar et al.

${ }^{1}$ See for example, Windel et al. (2011), A Methodological Review; Masten and Powell (2003), Resilience Framework; Southwick et al. (2013) Resilience Definitions.

ISSN: 2456-7620

https://dx.doi.org/10.22161/ijels.54.48
(2003) have provided clarification by distinguishing between resilience as a dynamic development process or phenomenon that involves the interaction of personal attributes with environmental circumstances, and resiliency, a term coined by Block \& Block, as a personality characteristic of the individual (Block \& Block, 2014). In other words, resilience means bouncing back against difficulties, and individuals with personality resilience have the positive characteristics that helps them achieve such an outcome more easily. Quite candidly though, the by now old question of whether resilience is a human trait, a process, or an outcome being answered merely through our brain behavior, cannot do justice to the multi-systemic nature of human existence in general and human resilience in particular. Current resilience models encourage what Howell and Voronka refer to as "a technology of looking inward" (Howell \& Voronka, 2012, p.4-5), where citizens like soldiers and their families (Howell, 2014), university students (Aubrecht, 2012), or foster youth (Hath \& Graydon, 2009) are dissuaded from questioning the context and are rather persuaded towards positive thinking and self-help. In some examples from the literature in the field, resilience scholars have pondered upon this dubiousness with what has been referred to as a 'paradox ${ }^{2}$.' For example, Martin writes about the possibility of looking at resilience in a way which "may not always be positive and, importantly, may disenfranchise the individual" (2015, p.117). Others, have been engaged with what has been referred to as 'the dark side of resilience.' For example, Kuhlicke explores the dark side of resilience in relation to power. Having studied resilience in relation to disaster management, Kuhlicke concludes that resilience has the ability to turn into a myth which may enable the players in power to "define what is right and what is wrong" (2013, p.61). Elsewhere, Atkinson and his colleagues revisit the concept in their attempt to warn against "dangers of popular movements based on uncertain evidence" (2008, p.144). As referred to by Atkinson et al., Masten and Obradovic's (2006) terminology, 'ordinary magic' also cautions against such risks, in particular by underscoring how ordinary resilience is and how wrong those who blame the individual for his vulnerability are. Although in this paper I will not engage with the definitional debates of the topic, I will use Masten's key components of resilience, her so-called "short list" of resilience factors (2007, p.926), to analyze my examples with the premise that current formulations of resilience are rather paradoxical.

${ }^{2}$ See for example, Atkinson et al. (2009) Resilience Revisited. 
The list includes the factors which resilience researchers from different fields (for example, psychology, psychiatry or sociology) believe to be supportive of a resilience outcome. These key words (see Masten, 2007), or resilience protective factors, are, for example: effective caregiving and parenting quality; close relationship with other capable adults; close friends and romantic partners; intelligence and problem-solving skills; self-control, emotion regulation, planfulness; motivation to succeed; self-efficacy; faith, hope, belief life has meaning, effective schools, effective neighborhoods, and collective efficacy. In the next two sections, I will identify the resilience attributes in the novels at hand, picture how each text can be read as an exemplary resilience story, and point out the analogy of approaches between the education to resilience and self-help manuals.

\section{A RESILIENCE READING OF THE POWER OF SYMPATHY}

Despite The Power of Sympathy's relative obscurity, the novel was a landmark in the history of world literature: it is said to be the first American novel. As the story opens in Boston, a young man named Thomas Harrington is conversing via letters with his friend Jack Worthy. Harrington confesses that he is passionately in love with a young woman named Harriet Fawcet; the story revolves around the fate of the lovers in an epistolary style until it finally reveals that they are half brother and sister. In despair at the horrific news, they both commit suicide. A resilience reading of this epistolary seduction novel reveals a few resilience protective factors, which are also relevant to selfhelp culture. I will first detail how the novel preaches specific resilience and self-help behaviours via an emphasis on education and adaptive skills and will afterwards discuss their one-sidedness and failure of resilience against overbearing social ills.

Education. As Brown indicates in his magazine writings, women are essential intellectuals for the natural aristocracy, and Mrs. Holmes emerges as a model intellectual in this novel. She sends many didactic letters to Harrington's sister, Myra, discussing topics ranging from education to religion. As one such letter makes clear, Mrs. Holmes views herself as part of a class of "learned ladies" who are "justly celebrated as ornaments to society, and an honour to the sex" (Brown, p.56). Within the pages of Brown's novel, Holmes acts as such an intellectual: she is the first to disclose that
Harrington and Harriot are blood relatives, and she works to stop their impending marriage.

In letter XI, in which she writes to Myra, Mrs. Holmes narrates the conversations between Mrs. Bourn and Worthy about the role of education, reading, and the choice of reading novels: "Novels, not regulated on the chaste principles of true friendship, rational love, and connubial duty, appear to me totally unfit to form the minds of women, of friends, or of wives" (Brown, p.28).

The emphasis put on the role of reading constructively can go hand in hand with the role of personality resilience. Resiliency research, maintain Werner and Smith (2001), brings attention to individuals' strengths and resources, often referred to as protective factors or mediators. Similarly, researchers like Masten (2007) have identified internal factors (e.g., ego resiliency) and environmental factors (e.g., family, society, culture) as two sources of these protective factors. Ego-resilience is grounded within the context of personality development and has been used to isolate defining characteristics of resilient individuals, such as "confidence, self-esteem, competent functioning, and a sense of mastery within a wide range of life domains" (Klohnen, p.1075).

Education, one of the lessons from Brown's novel, in the sense of reading methodically, will be of benefit to women, as they will not be confined to a limited "store of knowledge" (Brown, p.31). General reading will not teach a woman true knowledge of the world, rather, specific topics are suggested: faithfulness in friendship, constancy of true love, and the virtue of honesty. In short, voices Mrs. Holmes, "those books which teach us a knowledge of the world are useful to form the minds of females, and ought therefore to be studied" (p.34). The topics Mrs. Holmes singles out are suggestive of interpersonal skills that promote personality resilience. "The 'prosocial' personality traits may be grouped under the general concepts of sociability, emotional expressiveness, and interpersonal understanding" (Skodol, p.113). Therefore, in order for a woman to have knowledge of the world, reading and gaining second-hand experiences through literature are encouraged.

In self-help literature, not only on the individual level, but also in self-help groups, "information sharing and cognitive instruction" (Kurtz, p.105) have been observed as recurrent processes. Linda Kurtz's research results show that "self-helpers share 'experiential knowledge' which can only come from living with the condition" (p.105). In a recent 
study, Graaff and Klepper provide multiple case examples for the contextual immediacy of self-help practices. For example, they write ofmid nineteenth century Black self-help practices, which underscored "the imperatives of emancipation, literacy, self-confidence, and comprehensive education" (p.77). Current research in the field of education, claim Krasny et al (2009), asserts that learning is situated in real-world practice, and occurs through recursive interactions between individual learners and their social and biophysical environment, one case of which is encouraged by Brown's emphasis on the role of constructive conversations, and is crucial to both self-help and resilience.

Adaptation. The novel underscores the role of adaptive skills, a second key factor in resilience research. Mrs. Holmes is aware of the importance of understanding and adapting to dominant cultural models. She advises Myra, "Habituate your mind to remark the difference between truth and fiction," especially regarding potential suitors. She says marking this difference will allow Myra to be mindful of "insidious gentlemen, who plan their advances [...] on the chesterfield an system of flattery and duplicity" (Brown, p.53). More than being mindful of deceitful men, however, this knowledge also provides women with the means to adapt to the world as Mrs. Holmes words: "We owe ourselves a detestation of folly [...] Pretend, therefore, should a vain youth throw out illiberal sarcasms against $[\ldots]$ any serious subject, not to comprehend the point of his wit" (p.55). The emphasis is on the role of flexibility and adaptation to the reality of life, which, in Mrs. Holmes opinion, helps women avoid possible failures and negative outcomes. In that sense, the novel is an invitation to preparedness and wisdom in order to reduce possible negative results which, the novel suggests, stem from ignorance in the ways of the world.

Women are encouraged to learn from the seduction tales and stories, which are based on realities of their society, and to develop a method to preserve their grace. The role of flexibility and adaptability brings to mind Brown's focus on encouraging women to educate themselves, as is theorised by Masten in her 'short list,' reading books can act as a resilience protective factor, instigating self-awareness and wisdom.

\section{A CRITIQUE ON PROMOTING RESILIENCE VIA SELF-HELP IN THE POWER OF SYMPATHY}

Although the role of education in individual resilience can not be denied, one may wonder if education can be of any benefit when the society fails to fulfill its roles? In Brown's novel, women are encouraged to education in order to be resistant against frequent seductions. Should we not, instead, want to create a more morally correct society rather than taking women responsible for defending themselves against ungentlemanly conducts? Isn't the emphasis on self-help rather paradoxical when we consider how corrupt the context is?

Women's acts of resistance in the novel, their developed coping mechanisms, presumably transcends social class. The often-discussed scene where Harriot appears to seduce Harrington to virtue is once such exemplary moment. The opening of the scene seems to support this interpretation, for while Harrington begins by explaining to Worthy that their difference in class standing precludes their ability to marry, he quickly changes his mind. Harrington first writes, "Harriot has no father-no mother [...] I must take the liberty to acquaint you, that I am not so much of a republican to formally wed any person of this class" (Brown, p.11). Instead, he plans to "remove this fine girl into an elegant apartment, of which she herself is to be the sole mistress" (p.12). However, in his next letter, Harrington declares that the "all-conquering force of Harriot's eloquence" had reformed him into principles "the most just, and the most honorable" (p.14). As such, he decides to forgo the class difference and marry her in spite of his father's remonstrance. Their difference in social status hints at the problem of social inequality and how, as an environmental risk factor, poverty or lower class status can affect an individual's self-efficacy. Brown chooses to portray a picture of a strong woman who fights for her virtue despite her lower social class. Lack of personality resilience, or rather not being educated in those cases, makes women vulnerable to seductions which can be interpreted here as the exposure to risk. However, the questions asked in the beginning of this section circle back here. This virtuous woman, Harriot, eventually is defeated by the realities of the corrupted society in which her virtue can never be enough. Her and Harrington's suicide are testimonies of a resilience paradox: when the social context fails to fulfill its duties, in the case of this novel, a morally corrupt upper class, the resilience of the individuals can not survive the consequences.

In other words, Brown appears to be contending that when an individual learns how to adjust themselves to their society and its expectations and norms, they will be able to 
manage through life and its various stressors. Here, he espouses a view which is repeatedly referred to in resilience research: one's ability to adapt to one's context is a key factor in one's resilience. Similarly, he uses other characters to elaborate further about choice-making and adaptability. For example, in letter VII, Mrs. Holmes underscores how it is always a matter of choice when it comes to happiness, as "A GREAT proportion of our happiness depends on our own choice" and depends on our understanding of the "beauties of the mind" (Brown, p.19,22) and learning from "conversation of people of ideas" (p.26). It is in this regard that Brown also talks about "the principle of self-correction" in the context of education and reading 'useful' books, "for among all kinds of knowledge which arise from reading, the duty of self knowledge is a very eminent one; and is at the same time, the most useful and important" (p.40). However, as argued earlier, Brown's story implies that when the adversity is too overwhelming, when the social context is rather a risk factor, the person does not have a chance to develop. The end is suicide.

\section{A RESILIENCE-READING OF EDUCATED}

Educated is a benchmark inself-help and resilience. It is a narrative about how a disadvantaged girl takes control of her life. Reflecting on Educated from a resilience point of view brings to mind many of the attributes, protective and risk factors of resilience. For example, regarding Westover's childhood and teenage life, risk factors such as a dysfunctional family, lack of social and communal support, physical and psychological abuse, and lack of a nurturing environment alongside traumatic incidents like a car crash and daily work in the junkyard are prominent. In her college years, once again lack of family support is dominant; however, there is also the precious and scarce mentorship she receives from her brother Tylor and her community at the church, introduced to her by her flatmate. She also receives support from a constructive relationship with her professor who provides her with the further educational opportunity in Cambridge. Of importance is also her personal character, her resilient self, which despite breakdowns, keeps her moving forward until she reaches the assurance of self-love and selfrespect. In order to study these factors in a more contextualized manner, in the following sections I will discuss them in relation to textual examples.
Ego or personality resiliency. To briefly review what I mean by ego resilience, I would like to refer to Andrew E. Skodol's(2010) theorisations of the resilient personality. Speaking of individual differences which can lead to different responses to adversities, in which some people display resiliency and some become increasingly vulnerable, he writes:

Resilient personalities are characterized by traits that reflect a strong, welldifferentiated, and integrated sense of self (self-structure) and traits that promote strong, reciprocal interpersonal relationships with others. (113)

Self-structure may be the strongest trait in Westover's story. The picture Westover presents to us, even during the time she was living at home according to her father's rules, is never that of a weak girl. Expectedly though, Westover's coping mechanism changes with the change in her character. Alongside her struggle to have her own voice, her coping also changes from repressive coping and denial to reflective and constructive stress management. Before being who she is now, as a girl in a survivalist, dysfunctional family, experiencing injuries and beatings, she chooses to deny what the reality of her experiences was telling her, and instead accepts the justifications her parents provide, or rather always blames herself for any kind of negative incident. The following subsections provide examples of such incidents.

Having a Voice. When I reviewed the interviews, texts and the very few research papers written on Westover's book, a common response struck me. Both public and critical reception of the memoir praise the text as a story of selfeducation. Westover's memoir is written after her escape from her dysfunctional home, but she tells us that during the years she was living at home she kept a journal in which she wrote or rather reflected on the events of the day. However, she always writes Shawn's (her older abusive brother) version of events, that is, she used to write in Shawn's voice. But one night, she starts questioning this voice. The incident that triggers this series of self-doubts is her being violently beaten by Shawn at a shop, when after a day of work in the junkyard, in "clothes heavy with dirt," (Westover, p.193) oil and grease, Westover decides to stay in the car and wait for Shawn to do the shopping. Westover's refusal to leave the car is due to her spotting her boyfriend's car in the same 
parking lot, and not wanting to be seen in such a dirty shape, she asks to stay in the car. Shawn notices that her refusal to leave the car is because she doesn't want her boyfriend to see her like that. Shawn sees this occasion as an opportunity to reprimand her and says "Don't want your boyfriend see you looking glamorous?" (p.194). Westover writes that what happened after this line is a blur in her memories because "I see my hands grasping the wheel, and I feel strong arms wrenching my legs. Something shifts in my ankle, a crack or a pop. I'm pulled from the car" (p.194). He drags her outside the car, and inside the shop and only responds to her screams and hysterical nervous laughter by repeating "you are going in" (p.194). The situation carries on in this absurd manner. That night, back at home, she asks herself, "why didn't he stop when I begged him? It was like getting beaten by a zombie... like he couldn't hear me" (p.195)and continues "Was it really fun and games?" Could he not tell he was hurting me? I don't know. I just don't know" (p.195). Although this is the start of re-evaluating her entire family's behavior, that night she still tries to reason with herself. She tries to justify the incident as her fault for not asking Shawn calmly and politely enough, and writes:

I decide that if I asked differently, been more calm, he would have stopped. I write this until I believe it, which doesn't take long because I want to believe it. It's comforting to think that the defect is mine, because that means it is under my power. (emphasis original, 195)

What she is doing here is completely ignoring Shawn's act and focusing on herself. She tries to repeat the night in her mind the way she wants to believe it, but reality keeps coming back until finally she accepts what she has been fighting to reject: that her "humiliation" was Shawn's "objective" (p.196). It is this realisation that gives her the voice she had been denied for years. Westover writes:

Not knowing for certain, but refusing to give way to those who claim certainty, was a privilege I had never allowed myself. My life was narrated for me by others. Their voices were forceful, emphatic, absolute. It had never occurred to me that my voice might be as strong as theirs. (197)

Her self-reflective thoughts are in line with a narrative characteristic termed exploratory narrative processing, which is "broadly defined as the active, engaged effort on the part of the narrator to explore, reflect on, or analyze a difficult experience with an openness to learning from it and incorporating a sense of change into the life story" (Pals, p.1081). This narrative characteristic is further associated with coherent positive resolution, which is the "construction of a coherent and complete story of a difficult event that ends positively, conveying a sense of emotional resolution or closure" (p.1082). Westover's realization that she has a voice of her own is her step in an exploration which helps her observe how she has been writing her own journal in Shawn's voice, and how having always been dictated to what to think, she has never stopped to think about how she would want to think. Through exploratory narrative processing, she starts a journey of self-reflection that years later ends up in "emotional resolution, the presence of a coherently structured conclusion, and the valence of the narrative ending" (p.1083)- which she refers to as her education.

Coping mechanisms and an educated perception of the self.After finding her voice, she becomes reflective in a more self-defined and reality-based manner. This change of perspective is apparent in an often quoted sentence from Westover: "you can love someone and still choose to leave them" (interview with Oprah Winfrey). This quote directly reflects on how Westover eventually reaches the "sense of self," which is "evidenced by self-esteem, self-confidence or self-efficacy, self-understanding, a positive future orientation, and the ability to manage negative behaviours and emotions" (Skodol, p.114). In an interview with CNN, Westover talks about the process in which she finally learned how to manage negative emotions. For her, it was of utmost importance to acknowledge her desire to live a life outside her parents' definitions and to respect her own life. Entangled in this realization is her enhanced self-esteem and self-trust. As a child she chose to believe whatever her parents presented to her as truth, but after the incident at the shop with Shawn, her reflections become more self-defined and she starts the path towards thinking and living for herself, towards self-awareness.

In line with this resilience attribute, Skodol speaks of what has been termed "internal locus of control (p.114). $\mathrm{He}$ defines this as the manner in which resilient people believe that they are in control of their lives and are not affected by "fate, bad luck, or another person's behaviour" (p.114). In Westover's case, these external elements would be her parents' religious and anti-government beliefs. Her parents deeply believe that the Lord controls everything in their lives,hence, if one of them is burnt, they will also be healed by some miracle. They also believed in the 
Abomination day, that the world would end at the change of millennium in 2000 , and therefore chose a survivalist life style always preparing for doomsday. However, Westover does not see the world as "threatening, problematic, and distressing;" she doesnot see herself as "vulnerable" (p.115). In her final pages, she writes:

When my father was in my life, wrestling me for control of that life, I perceived him with the eyes of a soldier, through a fog of conflict. [...] what has come between me and my father is more than time or distance. It is a change in the self. (Westover, p.328)

Although she finally comes to the conclusion that she needs a new concept of self to put a stop to perceiving her father with an eye of the soldier, it is not before years of struggle. This reflection on her newly gained self is further put into a more concrete experience when she stares at her actual refection in the mirror one winter night as an educated woman. She is unable to call on her sixteen-year old self. She writes:

Until that moment she had always been there. No matter how much I appeared to change- how illustrious my education, how altered my appearance- I was still her. At best I was two people, a fractured mind. She was inside, and emerged whenever I crossed the threshold of my father's house. That night I called on her and she didn't answer. She left me. She stayed in the mirror. The decisions I made after that moment were not the ones she would have made. They were the choices of a changed person, a new self. (Westover, p.329)

For Westover, as for anyone to be resilient, the moment of self-realisation and the subsequent self-efficacy can be taken as the focal point. Had she stayed home, or had she chosen to remain that sixteen-year old, she would not have found her voice and her self-defined self in her life story. As is evident in the quote, perception of her selfdefined self outside and away from her father's version of her, or in resilience terminology, her "self-understanding," was a "critical initial task of [her] adult development" (Skodol, p.115).

Self-understanding goes hand in hand with three defense mechanisms introduced by the American Psychiatric Association (2000) and cited in Skodol's account: selfassertion, self-observation and sublimation (the other categories being affiliation, anticipation, altruism, and humor). Westover learns to express her feelings directly without manipulation (self-assertion). For example, on the same night that she reflected on Shawn's abusive behaviour and decided to write in her journal using her voice instead of his, she wrote, "if I was larger, at that moment, I would have torn him apart" (Westover, p.196) instead of, as she always did, justifying the incident as something she must have done inappropriately. She also learns to reflect on her own behavior, thoughts, and feelings, as is evident from the quotation above (self-observation). Finally, she manages to learn that instead of laughing hysterically, dreaming of tearing Shawn apart, or feeling constantly guilty after denying her dad's blessing, she needs to break the ties and move away from her family (sublimation). She learns to "channel potentially maladaptive feelings or impulses into socially acceptable behaviour" (Skodol, p.116).

"Odds are better if you rely only on yourself". This quotation is from the pages where Westover describes how and what she was thinking when working in the junkyard with her Dad. The importance of this quotation is how clearly it portrays Westover's thought processes in times of adverse experiences, underscored repeatedly in her memoir. She maintains that in her life experiences, for example when her Dad was "dumping the scrap bin" and she was standing on the bin, her instincts "had saved her" (Westover, p.102). Simply because her instincts "had understood, even if I had not, that it was better to fall from that great height rather than hope Dad would intervene" (Westover, p.102). Her instincts, she writes, always relied on one single motto: "that the odds are better if you rely only on yourself" (p.102). The question here is if Westover believed in this doctrine both before and after being "educated" and or how long she maintained this doctrine?

\section{A CRITIQUE ON PROMOTING RESILIENCE VIA SELF-HELP IN EDUCATED}

As a girl living in a family who taught her nothing but survival, her belief in "only depending on her own" (p.102) is rather understandable. However, could she have worked through her adult years had it not been for trusting that she can also depend on support from others? Throughout her narrative, there are many examples of her recovery or success which could not have been possible without external, non-familial support. Charles, her first boyfriend or as she 
calls him "the first friend from the other world," (p.185), played a great role in her life. He was the person who told her that her "behaviour was self-destructive, that [she] had an almost pathological inability to ask for help" (p.185). But Charles could not tolerate how Shawn behaved towards her and had to break up with her because "he [Charles] said he loved me but this was over his head. He couldn't save me. Only I could" (p.190). She didn't grasp what he meant by his words because even then she wasn't seeing what he was seeing - the behavior and condition of her family. She believed he was wrong, she had the ability to "lie convincingly to myself [herself]" (p.189).

Another person who was empathetically critical of Westover's behaviour was her second year college roommate, Robin. She acted as an older sister towards her, teaching her how to behave in the apartment in relation to others, encouraging her to go see the doctor for her broken toeor her stomach ulcers, and encouraging her to talk to the bishop about her financial problems. Initially, Westover rejects all of her suggestions. She trusts herself and her belief in her ability to do anything, which is confirmed/affirmed when she passes an algebra test with the score of one hundred, on her own, without anyone's help. For her, this was the proof that "nothing touches me [her]" (Westover, p.191). However, Robin persisted and finally "I [Westover] stood outside the bishop's office on a cold night in February. I didn't know what had taken me there" (p.200).

Later on, Dr. Kelly, her history professor, introduces her to Cambridge University. Her time in Cambridge consolidates the changes in Westover's self. Professor Steinberg in Cambridge and Dr. Kelly both provide her with great mentorship, not only for Westover to become a successful scholar, but also for her to be who she is. On her last night at Cambridge, over dinner, Dr. Kelly tells her, "the most powerful determinant of who you are is inside you" (p.243). Similarly, after winning the Gates scholarship, while studying in the library of Trinity college, she receives a song sent to her by a friend from BYU. The lyrics of this song summarize Westover's path in her resilience and success:

Emancipate yourselves from mental slavery

None but ourselves can free our minds. (257)

Graaff and Klepper maintain that "self-help narratives by white authors commonly portray the existing conditions as something that can be molded at the subject's will” (p.91). Although arguably Westover's exemplary wellearned emancipation is greatly dependent on her personal resources, the story may seem to be masking the crucial role contextual factors played in her success. Paradoxically, many passages in the memoir refer to the personal factors. Her professor in Cambridge, Dr. Kerry, had similar observations about her. At the last dinner at Cambridge, he talks to Westover about how he has been observing her behavior and how he believes she acts as if she is someone else, someone who does not belong to a place like Cambridge. He shares some words of wisdom that resonate with the song lines above: "Whomever you become, whatever you make yourself into, that is who you always were. It was always in you. Not in Cambridge. In you" (Westover, p.242). Although the role of individual resilience can not be denied in any success story, Westover's memoir downplays the significant role of her supportive system: her younger brother Taylor who initiated her education; her supportive roommate; her career-initiating professors and also her church. If in The Power of Sympathy, Harrington and Harriot committed suicide to escape the vice of their society, Westover's social context acted, at least in her adult academic life, as a mediator supporting her eventual education, self-awareness and self-help.

\section{CONCLUSION: EDUCATION, SELF- HELP, AND RESILIENCE}

Whether, as Elisabeth Deed Ermarth(1992) writes, the boom in self-help book sales may be related to the ways "postmodern subjectivity constructs self-reflexive subjectsin-process (p.58), so that the individual's infatuation with self-invention acts as a tool for social control (McGee, p.2223); or whether self-help literature is a "strategy for enlisting subjects in the pursuit of self-improvement and autonomy" (Rimke, p.61), one cannot deny its popularity and hence the effect on its readers' opinions, perceptions, and education.

With this paper I attempted to portray how the concept of self-help is conveyed through different forms of self-education and how the individuals and their contexts need to be both taking responsibility for a resilient outcome (or process) and a one-sided emphasis on the individual does not do justice to the complexity of the concept of resilience and its contextual factors.

Firstly, in The Power of Sympathy, Brown regards self-education and adaptive skills informed by reading as a means toward resistance, self-awareness and resilience. 
Adaptive skills, learning to adjust to various life challenges, is another form of self-education whereby the individual learns how to be flexible and how to maintain balance despite difficulties. An educated, adaptable person will be able to help himself and locate paths to resilience. Secondly, as was discussed in Educated, education is finding one's own voice. Westover's memoir depicts this emphasis on reading and learning and shows the effect of education on selfawareness and finding a self-defined voice.

As both works show, self-awareness and having one's own voice are prime manifestations of self-help culture and can be achieved by the persistent and resistant individual. However, one should not forget that to be resilient ina dysfunctional social context seems to be rather a resilience paradox: Individual's protective resources can only end in positive results when such resources are supported by the contextual factors as well. On the one hand, the emphasis on education, adaptive skills, self-awareness and finding one's voice indicates how these protective factor fosters positive outcomes and healthy personality characteristics despite unfavorable or aversive life circumstances; on the other hand, maintaining resilience is being underscored merely as an individual responsibility. Such a perspective, enables a dis-able society to keep defining behaviors- in the case of this article, human resilience- as desirable and normative without questioning the problematic nature of a society that demands its individuals to act resilient. It may be a high time to stop looking for resilience as a taken-forgranted response in any and all situations and ask why the context in which such individuals live should not be supportive and resourceful enough so that individual strength against difficulties would not be the only accepted and expected normal response.

As Graaff and Klepper have argued, "self-help creates its own self (or self-design/personality). It provides action/body-oriented instructions on how to manage (oneself in) the world" (p.78), but 'the world' and its role in resilience should not be ignored. According to the literary examples in this article, social context plays as defining a role- if not more- as the individual, making the present emphasis on selfhelp and resilience a paradoxical response in times when the social contexts need to be questioned for their availability of resources.

\section{REFERENCES}

[1] Block, J.H., and Block, J.(2014). The role of ego-control and ego-resiliency in the organization of behavior. In W.A.
Collins. (Ed.).Development of cognition, affect, and social relations, (p. 49-112).Routledge.

[2] Brown, William H. The Power of Sympathy. Penguin, 1996. Ohio State University Press. Web. 10 Jul. 2019.

[3] Ermarth, E.D. (1992).Sequel to History: Postmodernism and the Crisis of Representational Time. Princeton University Press.

[4] Emerson, R. W. (2018).Compensation. CDED.

[5] Farrar, Mrs J. The Young Lady's Friend. American Stationers' Company, 1837. books.google. Web. 10 Feb. 2020.

[6] Graaff, Kristina and Martin Klepper. (2020). Self-Help and/in Mass Cultures: Performatives of (Self-) Management and Race between 1890 and 1930. In J. Dorson and J. Verlinden. (Eds.),Fictions of Management: Efficiency and Control in American Literature and Culture, (p. 73-99), Heidelberg: Winter Verlag.

[7] Klohnen, E.C. (1996).Conceptual analysis and measurement of the construct of ego-resiliency. Journal of Personality and Social Psychology, 70(5), 1067-1079.

[8] Krasny, M.E., Tidball, K.G.\&Sriskandarajah, N.(2009). Education and resilience: Social and situated learning among university and secondary students." Ecology and Society14(2). Retrieved August 10, 2020, from www.jstor.org/stable/26268335

[9] Kurtz, L.F. (1990). The Self-Help Movement: Review of the Past Decade of Research.Social Work with Groups 13(3), 101115.

[10] Luthar, S.S., Cicchetti, D.,\& Becker, B. (2000). The Construct of Resilience: A Critical Evaluation and Guidelines for Future Work.Child Development, 71(3), 543-562.

[11] Masten, A.S. (2001). Ordinary magic: Resilience processes in development.American Psychologist56(3), 227-238.

[12] ---. (2007). Resilience in developing systems: Progress and promise as the fourth wave rises." Development and Psychopathology19, 921-930.

[13] McGee, M. (2005). Self-help, Inc.: Makeover Culture in American life. Oxford University Press on Demand.

[14] Newton, S.E. (1994).Learning to Behave: A Guide to American Conduct Books Before 1900(No. 28). Greenwood Press.

[15] Pals, J.L. (2006). Narrative identity processing of difficult life experiences: Pathways of personality development and positive self-transformation in adulthood. Journal of Personality, 74(4), 1079-1110.

[16] Rimke, H.M. (2000). Governing citizens through self-help literature. Cultural Studies, 14(1), 61-78.

[17] Sigourney, L.H. (1853). Letters to my pupils: With narrative and biographical sketches. books.google

[18] ---. (1850).Letters to young ladies. Harper: books.google.

[19] Simonds, W. (1992).Women and Self-help culture: Reading between the lines. Rutgers University Press.

ISSN : 2456-7620 
[20] Skodol, A.E. (2012). The resilient personality. In John W. Reich, Alex J. Zautra, and John Stuart Hall (Eds.).Handbook of Adult Resilience, (p. 112-125) NY:Guilford Press.

[21] Smiles, S. (1836). Self-Help; with illustrations of character and conduct. Boston: Ticknor and Fields.

[22] Southwick, S. M., Bonanno, G. A., Masten, A. S., PanterBrick, C., \& Yehuda, R. (2014). Resilience definitions, theory, and challenges: Interdisciplinary perspectives. European
Journal
of
Psychotraumatology,
$5(1)$, 25338.https://doi.org/10.3402/ejpt.v5.25338.

[23] Ungar, M. (2004) A constructionist discourse on resilience: Multiple contexts, multiple realities among at-risk children and youth.Youth \& Society35(3), 341-365.

[24] VandenBos, G. R. (Ed.). (2007). APA Dictionary of Psychology. American Psychological Association.

[25] Werner, E.E. (1992). Overcoming the odds: High risk children from birth to adulthood. Cornell University Press.

[26] Werner, E.E., \& Smith, R.S. (2001).Journeys from childhood to midlife: Risk, resilience, and recovery. Cornell University.

[27] Westover, T. (2018)Educated: A Memoir. New York: Random House.

[28] ---. Oprah Talks to Tara Westover. Interview by Oprah Winfrey. Youtube May 2019.

[29] Windle, G., Bennet, K. M., and Jane Noyes, J. (2011).A Methodological Review of Resilience Measurement Scales. Health and Quality of Life Outcomes, 9(8). https://doi.org/10.1186/1477-7525-9-8 